\title{
High-resolution barotropic modeling and the calving of the Mertz Glacier, East Antarctica
}

\author{
C. Mayet, ${ }^{1}$ L. Testut, ${ }^{1}$ B. Legresy, ${ }^{1}$ L. Lescarmontier, ${ }^{1}$ and F. Lyard ${ }^{1}$ \\ Received 11 May 2012; revised 3 July 2013; accepted 6 August 2013; published 15 October 2013.
}

[1] In February 2010, the Mertz Glacier Tongue (MGT) calved, releasing an $80 \times 40 \mathrm{~km}$ iceberg. We have developed a high-resolution barotropic ocean model of the region to simulate the local circulation in response to tides and atmospheric forcing. We improved the coastline, grounding line position and built a new bathymetry using satellite imagery and older bathymetry data to derive the best available tidal model for the region. We compared this and other available models to seven different sea level observations available in the area and significantly improved the tidal solutions reaching a root sum square of $2.3 \mathrm{~cm}$. This model was then run in different bathymetric configurations, considering the ice draft of the major icebergs $\mathrm{B} 9 \mathrm{~B}$ and $\mathrm{C} 28$, to simulate the circulation before, during, and after the calving event. The currents changed substantially in the neighborhood of the MGT and icebergs. The barotropic model with tidal and atmospheric forcing and the atmospheric wind fields allow us to evaluate the forces acting on the MGT. The sea surface slope force dominates the budget. Calving occurred when high tide and strong nontidal currents (due to atmospheric forcing) combined to lead to the monthly maximum forces exerted on the MGT (i.e., between 10 and 13 February 2010). While the forces are not unusually large at the calving time, the currents are largely enhanced in the rifting area. Therefore, processes related to these currents, like melting the ice mélange inside the rifts, should be investigated to fully explain the final stage of the calving.

Citation: Mayet, C., L. Testut, B. Legresy, L. Lescarmontier, and F. Lyard (2013), High-resolution barotropic modeling and the calving of the Mertz Glacier, East Antarctica, J. Geophys. Res. Oceans, 118, 5267-5279, doi:10.1002/jgrc.20339.

\section{Introduction}

[2] In February 2010, the Mertz Glacier Tongue (hereafter MGT) in East Antarctica $\left(67^{\circ} \mathrm{S}, 146^{\circ} \mathrm{E}\right)$ calved and released an $80 \times 40 \mathrm{~km}$ iceberg (C28). The Mertz is one of the main glaciers of the East Antarctic ice sheet and any disturbance in its flow is expected to have a large impact on the ice dynamics of the surrounding area. Calving involves very different time scales, from several decades of ice tongue development through several years of rifting down to the sudden final separation.

[3] Periodic sea level variation (tides, swell) and tidal currents are known to play an important role on the opening of fatigue cracks on the ice tongue [Legresy et al., 2004]; however, the progress of a calving event is still largely unknown. The MGT Calving event was extensively studied in the framework of the French Cooperative Research into Antarctic Calving and Icebergs Evolution (CRACICE) project which monitored the calving using Global Positioning System (GPS) devices installed on the MGT [Lescarmontier

${ }^{1}$ Laboratoire d'Etudes en Géophysique et Océanographie Spatiales, Toulouse, France.

Corresponding author: C. Mayet, Laboratoire d'Etudes en Géophysique et Océanographie Spatiales, 14 Ave. Edouard Belin, FR-31400 Toulouse CEDEX, France. (clement.mayet@legos.obs-mip.fr)

C 2013. American Geophysical Union. All Rights Reserved. 2169-9275/13/10.1002/jgrc.20339 et al., 2012; Lescarmontier, 2012]. The calving event occurred after a giant iceberg (hereafter B9B) moved toward and possibly hit the tip of the MGT. The changing position of B9B during the few days prior to the calving event is expected to have modified the ocean circulation around the MGT. We have developed a high-resolution ocean model in order to evaluate the impact of the modified circulation on the calving of the MGT. We have used a 2-D barotropic model implemented on a high-resolution finite element grid that can resolve the water depth change due to different B9B location, because the high-frequency velocity field is dominated by barotropic currents. The model, which includes the dynamical processes of the tides and high-frequency ocean response to atmospheric forcing, was used to estimate the modification of the circulation and forces exerted by the ocean on the MGT at the time of the calving. This paper focuses on the impact of the modification of the ocean circulation on the MGT. Section 2 is devoted to the presentation of the model setup and its different configurations. Section 2.1 details the model validation against available in situ data. In section 2.2, we discuss the main results and conclusions are summarized in section 2.3.

\section{Model Setup}

\subsection{The Hydrodynamic Model}

[4] The hydrodynamic model we used is the standalone 2-D barotropic shallow water module of the Toulouse 
Unstructured Grid Ocean model (T-UGOm). T-UGOm is a finite element 3-D Eulerian model based on unstructured grids and its 2-D module is the follow up of MOG2D [Carrere and Lyard, 2003]. This module is based on the wave equation formulation of the shallow water equations [ Lynch and Gray, 1979] to accurately model tides [Pairaud et al., 2008]. The advantage of the unstructured grid is that the horizontal spatial resolution can be increased in regions of necessity (on steep bathymetric slopes, near the coast, around the MGT) whilst keeping a reasonable number of mesh vertices. T-UGOm has a time splitting system which allows the unstable nodes to be dynamically identified and run in a subcycle with a smaller time step, thereby reducing the computation time. For a more detailed description of the model, see Le Bars et al. [2010].

[5] The accuracy of the model critically depends on accurate knowledge of the mean water column thickness, depending itself on the bathymetry and ice draft. Working at high latitudes implies some difficulties in defining the model geometry. First, the presence of ice all along the shore makes it difficult to locate the sea-land limit. For the model, this limit must be set where the water column thickness vanishes, which generally corresponds to the coastline. However, when floating ice is present, the zero water column thickness limit is the grounding line (the limit between floating and grounded ice). In the case of the Mertz Glacier, the cross-shore distance between the ice front and grounding line is about 150 $\mathrm{km}$, considerably modifying the model geometry, and the grounding line is $1100 \mathrm{~m}$ below sea level. Another difficulty is the presence of permanent sea ice which blocks ship access to measure bathymetry. Finally, in the presence of icebergs or floating ice tongues, the ice draft has to be subtracted from the bathymetry to get the water column thickness, which is the required parameter for the 2-D model. Each of these difficulties has to be addressed in the model to ensure accurate modeling of ocean circulation.

\subsection{Coastline}

[6] To get a precise coastline, we started from the highresolution AATC2003 (Australian Antarctic Territory Coastline) data set, which includes the position of the edge of permanent ice and the approximate grounding line, both of which are derived by remote sensing interpretation [Lorenzin, 2003]. We then updated the position of the Mertz Glacier grounding line from Interferometric Synthetic Aperture Radar (InSAR) data [Potzsch et al., 2000; Legresy et al., 2004]. High-resolution images (5 m) from the Système Probatoire d'Observation de la Terre (SPOT5) satellite (CCentre National d'Etudes Spatiales (CNES) 2010) allowed us to locate the coastline by color contrast (between rocks and water or sea ice) or by locating the tidal cracks in the images.

\subsection{Bathymetry}

[7] For the bathymetry, we started from the General Bathymetric Chart of the Oceans (GEBCO) 1 min grid global bathymetry (http://www.gebco.net/data_and_ products/gridded_bathymetry_data/) in which we embedded a high-resolution local bathymetry which is more detailed and uses more ship sounding data (see Beaman et al. [2010] for a detailed description). However, under the MGT, where no data are available, this bathymetry is erroneously an interpolation between the nearest known depth offshore and $0 \mathrm{~m}$ at the grounding line. In fact, at the grounding line the ice draft is $1100 \mathrm{~m}$, corresponding to the bathymetric depth there.

[8] To get a better bathymetry, we recalculate the data over the ice covered area. We used the coastline (which is the grounding line for the glacial ice covered part) that we determined in this study, the knowledge of the ice draft at the grounding line and the nearest offshore bathymetry values to interpolate the bathymetry across this area. We ensure a minimum of $20 \mathrm{~m}$ of water column thickness where we know that the ice is floating.

[9] Given these ice drafts and the monitored trajectories of the icebergs (mainly the B9B) during the year 2010 (using ENVISAT advanced synthetic aperture radar (ASAR), SPOT, and Moderate Resolution Imaging Spectroradiometer (MODIS) imagery), we modified the bathymetry where necessary so that the icebergs do not get grounded. The modifications were up to a few hundred meters in places, showing the need for a large improvement in the bathymetry especially at the east of the MGT where almost no data exist. Our reconstructed bathymetry, although improved to the best of our knowledge, is not always very accurate. In particular, the icebergs are not strictly always floating and get grounded at some points, and large areas are still unexplored. Since the calving event and now that the B9B iceberg cleared the area, it is now possible to observe the bathymetry of this unexplored area, which should happen in the next few years through the SUBMERTZ project (supported by Institut polaire français (IPEV), the French Polar Institute).

[10] Finally, the area covered by the MGT and the multiyear fast ice to the immediate east of the ice tongue [Massom et al., 2010] has not been surveyed. Following the analysis by Domack [1982], we include a trench that links the Ninnis Trench to the Mertz Trench and Adélie Depression in order to fit with paleotrajectories of glaciers.

[11] From our final bathymetry (see Figure 1), we built several maps of effective bathymetry (water column thickness), reducing bathymetry by the ice drafts of the MGT and $\mathrm{B} 9 \mathrm{~B}$ iceberg for the different configurations investigated herein, according to the monitored iceberg trajectories during the year 2010 (from satellite imagery), as described in the section 2.4. A different mesh is generated for each of these configurations.

\subsection{Ice Drafts}

[12] Our modeling approach assumes that icebergs can move vertically with the free ocean surface, but cannot move horizontally. In the case of the MGT, this assumption is verified because the ice tongue is rigidly linked to the continent. For the B9B iceberg, in the configurations studied in this paper, its free drift is constrained by grounding or landfast sea ice. Hence, the icebergs only modify the water column thickness. In the model, this is characterized by a different effective bathymetry as described in section 2.3. Modeling iceberg trajectories would require us to parameterize the forces acting on the iceberg and advect the icebergs' position, dynamically modifying the water column thickness, which is not the aim of this study. 


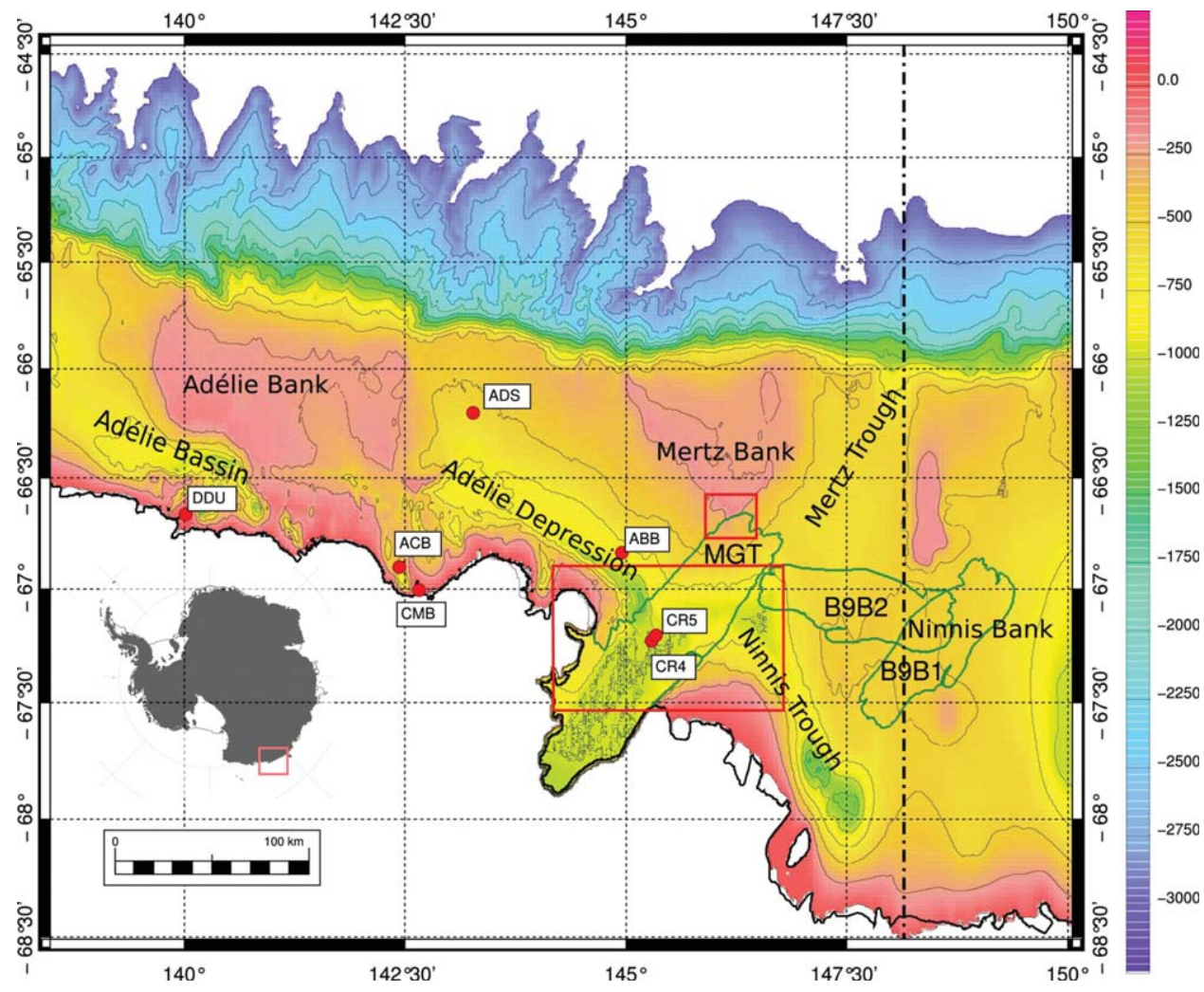

Figure 1. Background bathymetry (in meters) used by the model. Iceberg drafts were added to this bathymetry to obtain the different model configurations. The green lines indicate the position of the MGT, and of the B9B iceberg in position B9B1 and B9B2. The red dots indicate the location of in situ devices used to validate the model and the red boxes indicate the zoom regions shown in Figure 4. The vertical dashed line shows the eastern limit of the bathymetry from Beaman et al. [2010].

[13] The B09 iceberg calved off the Ross Ice Shelf in 1987 and crossed the Ross Sea [see Keys et al., 1990]. Near Cape Adare, B09 broke into three main pieces including B9B which drifted along the East Antarctic coast and eventually grounded on the Ninnis Bank in the early 1990s. B9B rested on the Ninnis Bank for almost two decades, slowly drifting south by a few kilometer during that period. This B9B position corresponds to the first model configuration, B9B1, in which the B9B iceberg was located east of the MGT and its exact location was derived from ENVISAT satellite ASAR images from the year 2009 (see Figure 1). In December 2009, B9B started to travel south and progressively turned west and northwest in January 2010 to arrive in contact with the MGT in early February 2010. Thus, for the second model configuration (B9B2), B9B was moved to be near the MGT using the ENVISAT ASAR image for the 6th of February. We drew the contours from satellite imagery and set a constant ice draft of $300 \mathrm{~m}$. As for B9B, a lighter density is guessed and we take $350 \mathrm{~m}$ as total thickness, $300 \mathrm{~m}$ draft as a guess without precise knowledge of the snow layer.

[14] We built a map of the ice draft for the MGT from airborne radio echo soundings (Italian Antarctic Expedition 2000 [Legresy et al., 2004]), freeboard from satellite altimetry and SPOT5 HRS (high-resolution stereo instrument) (C) CNES 2010) stereo imagery. The ice draft was computed by combining radio echo sounder (RES) thickness and surface topography to estimate a density profile along the MGT applying it to estimate the underwater thickness and extending across flow according to the imagery.

\subsection{Mesh}

[15] The mesh element size is calculated locally according to two criteria based on the tidal wavelength and the bathymetry slope [see Le Bars et al., 2010]. The effective bathymetry is interpolated onto the mesh vertices. In order to accurately represent the steep slopes in the model, mainly in transition areas between open waters and floating ice a different mesh has been computed for each iceberg configuration (see Figure 2). The resolution at the coastline is typically about $1 \mathrm{~km}$ and up to $45 \mathrm{~km}$ at the open ocean boundary. The grid cells reduce down to $100 \mathrm{~m}$ in areas of steep slopes or complex coastline, giving a total of about 22,000 nodes.

\subsection{Forcing and Boundary Conditions}

[16] The open boundary conditions were taken from the global tidal atlas Finite Element Solution (FES2004) [Lyard et al., 2006] which contains the harmonic coefficients of the tidal elevation of 15 main tidal constituents (2N2, K1, K2, M2, M4, Mf, Mm, Msqm, Mtm, N2, O1, P1, Q1, S1, S2). FES2004 does not provide the tidal currents, we made an intermediate run of the tidal model, forced by FES2004, on a larger area than our study (from $90^{\circ}$ to $160^{\circ}$ 
(a)

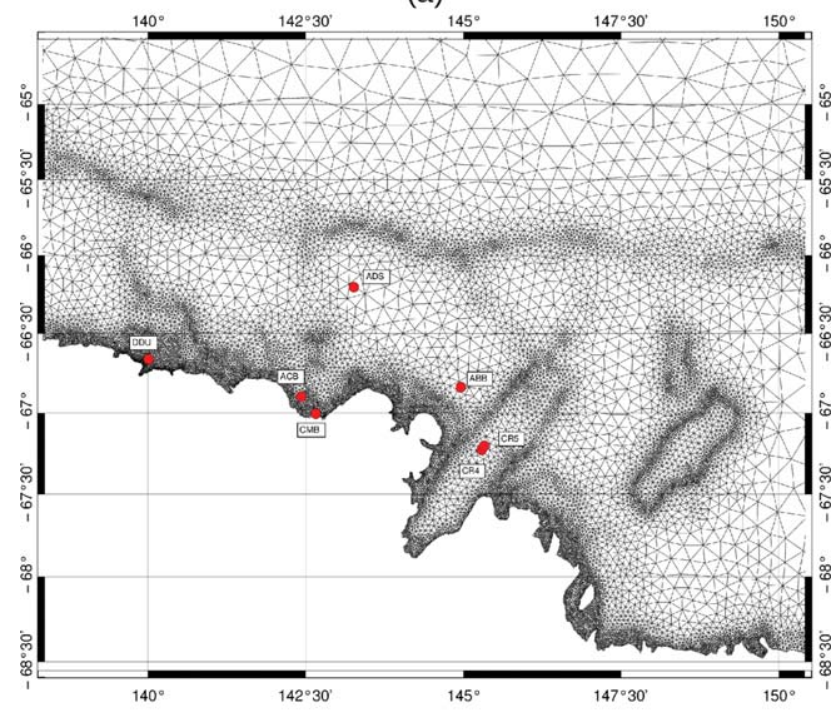

(b)

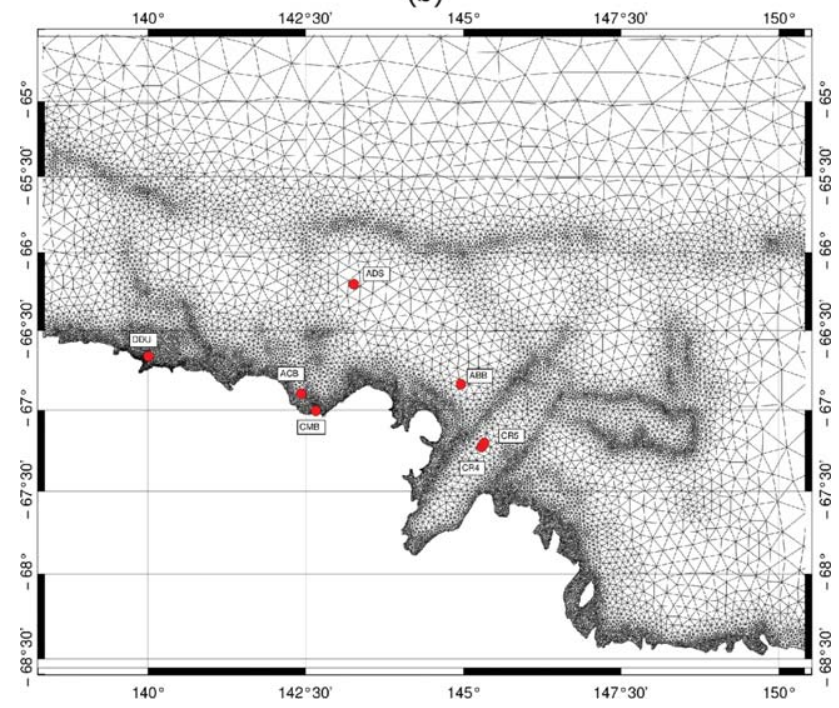

Figure 2. Detail view of the mesh for (a) B9B1 and (b) $\mathrm{B} 9 \mathrm{~B} 2$ bathymetric configurations. The red dots indicate the location of in situ devices used to validate the model.

East and from the coast to $60^{\circ}$ South, pushing the limits to a minimum of $330 \mathrm{~km}$ from the restrained domain sides), to get precise tidal currents to prescribe at the boundaries of our domain.

[17] For the simulations with atmospheric forcing (sea level pressure and wind at $10 \mathrm{~m}$ above the sea level), the pressure and wind field are taken three hourly from
European Centre for Medium-Range Weather Forecasts (ECMWF) Re-Analysis (ERA) Interim reanalysis and the three-hourly currents at the open boundaries were prescribed from global surge simulations as described in Carrere and Lyard [2003], which are computed in an operational mode for the $\mathrm{CTOH}$ (Centre de Topographie des Oceans et de l'Hydrosphere, http://ctoh.legos.obsmip.fr/). The wind stress is applied everywhere on the sea surface, not taking into account the sea ice cover.

\section{Validation}

[18] For the model validation, we used data from seven tide gauges: two (DDU and CMB) are coastal tide gauges of the ROSAME network (www.legos.obs-mip.fr/observations/rosame/), two (CR4 and CR5) are GPS beacons deployed on the MGT, from the CRACICE project (see Lescarmontier et al. [2012] for a detailed description), and three are bottom pressure sensors from acoustic Doppler current profiler (ADCP) moorings (ALBION project [Lacarra et al., 2011]). The tide gauges location are shown in Figures 1 and 2, and validation data set detailed in Table 1.

[19] To validate the tide model, we first extracted the tidal signal from the observed sea level time series. This is done by harmonic analysis which consists of decomposing the total signal in a certain number of sinusoidal waves of known period. We have used the harmonic analysis software routinely used by the Laboratoire d'Etudes en Géophysique et Océanographie Spatiales (LEGOS) tidal group for tide gauge and altimetry data analysis [Le Provost et al., 1998], which includes nodal modulation effects and admittance extension to allow for short time series analysis (i.e., less than 1 year record). For each wave, we get the harmonic coefficients (amplitude $A$ and phase lag $\phi)$. We analyzed a set of 20 principal tidal waves (the 15 constituents from forcing and boundary conditions, plus the nonlinear waves generated inside the domain). We ordered the waves by importance of their amplitude. The seven smaller waves have very small amplitudes and do not participate significantly to the error budget. Hence, the results of the validation are shown for the eight principal components (Tables 2 and 3).

[20] The same analysis is performed on the model outputs for the 1 year tide simulation, allowing us to compare the harmonic coefficients from the model and observations. The difference between modeled and observed harmonics is hereafter considered as the model error.

[21] The model error at one location for one tidal wave can be estimated from the modulus of the complex difference $|\Delta z|=\left|z_{o}-z_{m}\right|$, as shown by Andersen et al. [1995],

Table 1. Available Data for Validation of the Model Outputs on Tidal Elevation (B.P Stands for Bottom Pressure Sensor)

\begin{tabular}{|c|c|c|c|c|c|c|c|}
\hline & Location & Longitude & Latitude & Type & Sampling & Length & Source \\
\hline $\mathrm{ABB}$ & Buchanan Bay & $144.958^{\circ} \mathrm{E}$ & $66.838^{\circ} \mathrm{S}$ & B.P & $1 \mathrm{~h}$ & 1 year & ALBION \\
\hline $\mathrm{ACB}$ & Commonwealth Bay & $142.432^{\circ} \mathrm{E}$ & $66.899^{\circ} \mathrm{S}$ & B.P & $1 \mathrm{~h}$ & 1 year & ALBION \\
\hline CMB & Commonwealth Bay & $142.659^{\circ} \mathrm{E}$ & $67.006^{\circ} \mathrm{S}$ & B.P & $20 \mathrm{~min}$ & 1 year & ROSAME \\
\hline CR4 & Mertz Glacier Tongue & $145.291^{\circ} \mathrm{E}$ & $67.229^{\circ} \mathrm{S}$ & GPS & $30 \mathrm{~s}$ & 2 months & CRACICE \\
\hline CR5 & Mertz Glacier Tongue & $145.337^{\circ} \mathrm{E}$ & $67.205^{\circ} \mathrm{S}$ & GPS & $30 \mathrm{~s}$ & 2 months & CRACICE \\
\hline
\end{tabular}


Table 2. Validation Table for Global Models $(\sigma, \text { in } \mathrm{cm})^{\mathrm{a}}$

\begin{tabular}{|c|c|c|c|c|c|c|c|c|c|}
\hline & K1 & $\mathrm{O} 1$ & M2 & S2 & P1 & N2 & Q1 & K2 & $\sigma_{s}$ \\
\hline $\begin{array}{l}\text { Amplitude } \\
\text { FES2004 }\end{array}$ & 32 & 32 & 27 & 15 & 10 & 7 & 7 & 4 & \\
\hline $\mathrm{ABB}$ & 2.0 & 2.0 & 0.7 & 1.3 & 0.9 & 1.0 & 0.3 & 1.0 & 3.6 \\
\hline $\mathrm{ACB}$ & 1.4 & 2.0 & 0.9 & 1.0 & 1.1 & 0.8 & 0.5 & 0.6 & 3.2 \\
\hline ADS & 0.5 & 0.9 & 1.9 & 1.5 & 0.5 & 0.4 & 0.3 & 0.2 & 2.8 \\
\hline CMB & 0.7 & 1.2 & 0.4 & 0.4 & 0.3 & 0.6 & 0.1 & 0.7 & 1.8 \\
\hline CR4 & 3.3 & 2.4 & 1.6 & 1.8 & 1.1 & 0.7 & 0.8 & 1.0 & 5.1 \\
\hline CR5 & 2.3 & 2.5 & 1.1 & 1.5 & 0.7 & 0.7 & 0.5 & 1.2 & 4.2 \\
\hline DDU & 0.3 & 1.6 & 0.3 & 0.5 & 0.4 & 0.5 & 0.3 & 1.2 & 2.2 \\
\hline $\begin{array}{l}\sigma_{w} \\
\text { GOT4.8 }\end{array}$ & 1.8 & 1.9 & 1.1 & 1.3 & 0.8 & 0.7 & 0.5 & 0.9 & 3.5 \\
\hline $\mathrm{ABB}$ & 1.4 & 1.5 & 0.7 & 0.8 & 0.4 & 0.6 & 0.5 & 0.5 & 2.6 \\
\hline $\mathrm{ACB}$ & 4.0 & 2.9 & 1.2 & 1.4 & 1.9 & 0.6 & 0.9 & 0.4 & 5.8 \\
\hline ADS & 0.5 & 0.8 & 2.0 & 1.2 & 0.3 & 0.4 & 0.2 & 0.6 & 2.6 \\
\hline CMB & 3.6 & 2.1 & 0.1 & 0.6 & 0.7 & 0.3 & 0.4 & 0.4 & 4.3 \\
\hline CR4 & 1.6 & 1.6 & 1.3 & 0.8 & 0.3 & 0.0 & 0.5 & 0.2 & 2.8 \\
\hline CR5 & 2.2 & 1.5 & 1.3 & 0.6 & 0.5 & 0.4 & 0.5 & 0.1 & 3.2 \\
\hline DDU & 2.5 & 1.9 & 0.3 & 0.6 & 0.5 & 0.3 & 0.4 & 0.5 & 3.3 \\
\hline $\begin{array}{l}\sigma_{w} \\
T P X O 7.2\end{array}$ & 2.5 & 1.9 & 1.2 & 0.9 & 0.8 & 0.4 & 0.5 & 0.4 & 3.7 \\
\hline $\mathrm{ABB}$ & 0.7 & 1.2 & 1.4 & 1.2 & 1.5 & 0.8 & 0.5 & 0.6 & 3.0 \\
\hline $\mathrm{ACB}$ & 1.4 & 2.1 & 1.3 & 1.2 & 2.3 & 0.5 & 0.7 & 0.5 & 4.0 \\
\hline ADS & 0.7 & 1.7 & 2.1 & 1.6 & 0.8 & 0.3 & 0.3 & 0.4 & 3.4 \\
\hline CMB & 1.2 & 1.3 & 1.2 & 0.2 & 1.4 & 0.3 & 0.1 & 0.4 & 2.6 \\
\hline CR4 & 0.6 & 0.5 & 0.5 & 0.7 & 1.9 & 0.4 & 0.5 & 0.9 & 2.5 \\
\hline CR5 & 1.0 & 0.3 & 0.8 & 0.3 & 2.0 & 0.6 & 0.6 & 0.8 & 2.7 \\
\hline DDU & 2.1 & 2.0 & 1.3 & 0.4 & 1.0 & 0.3 & 0.2 & 0.2 & 3.4 \\
\hline$\sigma_{w}$ & 1.2 & 1.5 & 1.3 & 0.9 & 1.6 & 0.5 & 0.5 & 0.6 & 3.1 \\
\hline
\end{tabular}

${ }^{\text {a } T h e ~ w a v e ~ a m p l i t u d e ~ o b s e r v e d ~ a t ~ t h e ~ C o m m o n w e a l t h ~ B a y ~ t i d e ~ g a u g e ~ i s ~ i n d i c a t e d ~ u n d e r ~ e a c h ~ w a v e ~ n a m e . ~ T h e ~ f r a m e d ~ n u m b e r ~ i n ~ t h e ~ b o t t o m ~ r i g h t ~ c o r-~}$ ner is the RSS $(\mathrm{cm})$.

where $z=A e^{i \phi}$ and the subscript $o$ and $m$ stand for observation and model, respectively. This is directly related to the root mean square (RMS, noted $\sigma$ ) of the modeled and observed elevation difference time series:

$$
\sigma=\sqrt{\frac{1}{2}}|\Delta z|
$$

[22] The error for one given constituent at all sites is:

$$
\sigma_{w}=\sqrt{\frac{1}{2 N_{\text {sites }}} \sum_{N_{\text {sites }}}|\Delta z|^{2}}
$$

the total error of all the constituents at one site is:

$$
\sigma_{s}=\sqrt{\frac{1}{2} \sum_{N_{\text {waves }}}|\Delta z|^{2}}
$$

and the root sum square (RSS) which is the total error for all the constituents at all sites (the model error) is:

$$
R S S=\sqrt{\sum_{N_{\text {waves }}} \sigma_{w}^{2}}
$$

[23] We computed validation tables for recent global and regional tide models, these are:

[24] 1. A finite element hydrodynamic model with data assimilation, FES2004 [Lyard et al., 2006];
[25] 2. Two inverse models from altimeter data, TPXO7.2 [Egbert and Erofeeva, 2002], and GOT4.8 [Ray, 1999];

[26] 3. A $4 \mathrm{~km}$ regional model, with data assimilation, Circum-Antarctic Tidal Simulation (CATS2008) (an improved version of CATS 2002 [Padman et al., 2002]); and

[27] 4. Our regional model with two different bathymetries. These are the Mertz-old simulation, which uses the high-resolution regional bathymetry of Beaman et al. [2010], and the Mertz-b9b1 simulation, which uses our modified bathymetry as described in section 2.3 .

[28] Tables of model error $\sigma$ (in $\mathrm{cm}$ ) are shown in Tables 2 (global models) and 3 (regional models). Our regional modeling has clearly more skill in representing the tides in the Mertz region. The global models have RSS larger than $3 \mathrm{~cm}$ whereas the regional models all have RSS under $3 \mathrm{~cm}$. The Mertz-old model improved the RSS by about $10 \%$ against CATS2008. Finally, the Mertz-b9b1 configuration gives the best results with a RSS of $2.3 \mathrm{~cm}$, improved by $20 \%$ against CATS2008 and by $25 \%$ against TPXO7.2 (the global model best fitting the observations).

[29] A further validation of the model concerns the response to the atmospheric forcing. Lescarmontier et al. [2012] analyzed the vertical movements of the floating ice tongue using accurate GPS processing, decomposed the signal and retrieved tides, atmospheric response, and higher-frequency vibrations of the ice tongue. Lescarmontier et al. [2012] found, for periods of a few hours to a few days time scale, that most of the residual from the harmonic 
Table 3. Validation Table for Regional Models $(\sigma \text {, in } \mathrm{cm})^{\mathrm{a}}$

\begin{tabular}{|c|c|c|c|c|c|c|c|c|c|}
\hline & K1 & $\mathrm{O} 1$ & M2 & S2 & P1 & $\mathrm{N} 2$ & Q1 & K2 & $\sigma_{s}$ \\
\hline Amplitude & 32 & 32 & 27 & 15 & 10 & 7 & 7 & 4 & \\
\hline \multicolumn{10}{|l|}{ CATS2008 } \\
\hline $\mathrm{ABB}$ & 2.1 & 1.4 & 0.7 & 0.4 & 0.6 & 0.8 & 0.3 & 0.5 & 2.9 \\
\hline $\mathrm{ACB}$ & 0.9 & 2.5 & 0.8 & 0.8 & 1.6 & 0.6 & 0.8 & 0.3 & 3.5 \\
\hline ADS & 0.9 & 1.4 & 1.5 & 1.0 & 0.1 & 0.1 & 0.2 & 0.3 & 2.5 \\
\hline CMB & 1.8 & 2.6 & 1.2 & 0.7 & 0.6 & 0.5 & 0.3 & 0.3 & 3.6 \\
\hline CR4 & 2.2 & 0.4 & 0.6 & 1.2 & 0.5 & 0.4 & 0.7 & 0.7 & 2.9 \\
\hline CR5 & 2.7 & 0.6 & 0.5 & 1.0 & 0.7 & 0.5 & 0.7 & 0.7 & 3.3 \\
\hline DDU & 0.4 & 1.4 & 1.0 & 0.3 & 0.7 & 0.4 & 0.2 & 0.2 & 2.0 \\
\hline$\sigma_{w}$ & 1.8 & 1.7 & 0.9 & 0.8 & 0.8 & 0.5 & 0.5 & 0.5 & 3.0 \\
\hline \multicolumn{10}{|l|}{ Mertz-old } \\
\hline $\mathrm{ABB}$ & 1.0 & 1.0 & 0.5 & 1.1 & 0.6 & 1.0 & 0.5 & 0.9 & 2.5 \\
\hline $\mathrm{ACB}$ & 1.0 & 1.8 & 0.8 & 1.0 & 1.0 & 0.8 & 0.5 & 0.7 & 2.9 \\
\hline ADS & 0.4 & 1.0 & 1.9 & 1.5 & 0.4 & 0.4 & 0.3 & 0.9 & 2.9 \\
\hline CMB & 0.4 & 0.9 & 0.4 & 0.5 & 0.3 & 0.5 & 0.2 & 0.5 & 1.5 \\
\hline CR4 & 1.5 & 1.0 & 1.3 & 1.7 & 0.5 & 0.6 & 0.5 & 0.8 & 3.1 \\
\hline CR5 & 1.5 & 1.1 & 1.3 & 1.4 & 0.5 & 0.8 & 0.5 & 0.7 & 2.9 \\
\hline DDU & 0.6 & 1.1 & 0.4 & 0.4 & 0.1 & 0.6 & 0.3 & 0.6 & 1.6 \\
\hline$\sigma_{w}$ & 1.0 & 1.2 & 1.1 & 1.2 & 0.6 & 0.7 & 0.4 & 0.7 & 2.6 \\
\hline \multicolumn{10}{|c|}{ MERTZ-B9B1 } \\
\hline $\mathrm{ABB}$ & 0.5 & 0.6 & 0.5 & 1.1 & 0.2 & 1.0 & 0.6 & 0.9 & 2.1 \\
\hline $\mathrm{ACB}$ & 0.2 & 1.5 & 0.8 & 1.0 & 0.8 & 0.8 & 0.7 & 0.7 & 2.4 \\
\hline ADS & 0.2 & 0.9 & 1.9 & 1.5 & 0.4 & 0.4 & 0.3 & 0.8 & 2.8 \\
\hline CMB & 1.4 & 0.8 & 0.5 & 0.5 & 0.4 & 0.5 & 0.3 & 0.5 & 2.0 \\
\hline CR4 & 0.5 & 0.3 & 1.2 & 1.7 & 0.2 & 0.6 & 0.5 & 0.8 & 2.5 \\
\hline CR5 & 0.6 & 0.2 & 1.2 & 1.4 & 0.2 & 0.8 & 0.5 & 0.7 & 2.2 \\
\hline DDU & 1.5 & 0.3 & 0.4 & 0.4 & 0.4 & 0.6 & 0.4 & 0.6 & 1.9 \\
\hline$\sigma_{w}$ & 0.8 & 0.8 & 1.0 & 1.2 & 0.4 & 0.7 & 0.5 & 0.7 & 2.3 \\
\hline
\end{tabular}

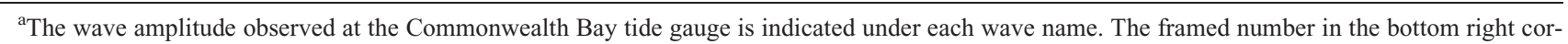
ner is the RSS $(\mathrm{cm})$.

analysis can be explained by the oceanic response to the atmosphere as modeled by the present version of the barotropic model.

\section{Simulations and Results}

[30] In order to evaluate the impact of the total barotropic velocity field (in response of tidal and atmospheric forcing) on the MGT calving event in February 2010, we ran the model in two different configurations corresponding to the different positions of the B9B iceberg, B9B1, and B9B2 as detailed in section 2.4.

[31] The model was run for 1 year with tidal forcing only and for the first 3 months of 2010 (period of the calving event) with tidal and atmospheric forcing (pressure and wind) from ECMWF (see section 2.6). In addition to these simulations, we followed the evolution of the B9B and C28 iceberg positions using mainly MODIS (C NASA) and ENVISAT ASAR (C ESA) satellite images. The main tool used during the calving of $\mathrm{C} 28$ has been ENVISAT ASAR as the cloud cover prevented the acquisition of useful visible imagery most of the time (Note: the series of available images have been aligned, dated, and mapped into a common projection and grid and will be available on the CRACICE website.)

\subsection{Forces Analysis}

[32] Icebergs drift and forces exerted on them have been described in a number of studies [e.g., Keghouche et al., 2009] and can be summarized as:

$$
M \frac{d u}{d t}=F_{t a}+F_{p a}+F_{t w}+F_{p w}+F_{s s}+F_{c}+F_{e}
$$

where $M$ is the iceberg mass, $u$ is the iceberg's velocity vector, $F_{t a}$ is the surface atmospheric drag, $F_{p a}$ is the lateral atmospheric pressure (form drag), $F_{t w}$ is the bottom water drag, $F_{p w}$ is the lateral water pressure, $F_{s s}$ is the force due to sea surface slope, $F_{c}$ is the Coriolis force, and $F_{e}$ is all external forces (sea ice, other icebergs, bottom drag on the ground). In the cases that we model, $F_{e}$ is very large so that icebergs are not moving or just about to move. In Antarctic coastal areas, the large floating ice masses are often grounded or attached to the glaciers so the velocity $u$ is zero, and so is $F_{c} . F_{t w}, F_{p w}, F_{s s}$, and $F_{c}$ result from the oceanic circulation, well represented in the barotropic model. Five forces remain $\left(F_{t a}, F_{p a}, F_{t w}, F_{p w}\right.$, $F_{s s}$ ), for which we can evaluate their respective importance.

[33] We evaluate them for the C28 iceberg (the part of the MGT that calved) with a length $(L)$ of $80 \mathrm{~km}$, a width (w) of $40 \mathrm{~km}$, a draft $\left(h_{w}\right)$ of typically $400 \mathrm{~m}$, and a sail $\left(h_{a}\right)$ of $40 \mathrm{~m}$, and in the across glacier direction. We take typical values for the wind speed $V_{\text {air }}$ of $10 \mathrm{~m} / \mathrm{s}$, for the water currents $V_{w}$ of $0.1 \mathrm{~m} / \mathrm{s}$ and for the sea surface slope $(\sin (\alpha))$ of $10^{-7}$ (from the model results). We assume values of 0.0022 and 0.0055 , respectively, for the surface $\left(C_{d a}\right)$ and bottom $\left(C_{d w}\right)$ drag coefficients, following Keghouche et al. [2009]. We assume a density for the water $\rho_{w}=1028 \mathrm{~kg} / \mathrm{m}^{3}$ and air $\rho_{\text {air }}=1.29 \mathrm{~kg} / \mathrm{m}^{3}$. The estimated orders of magnitude of the forces are as follow: 

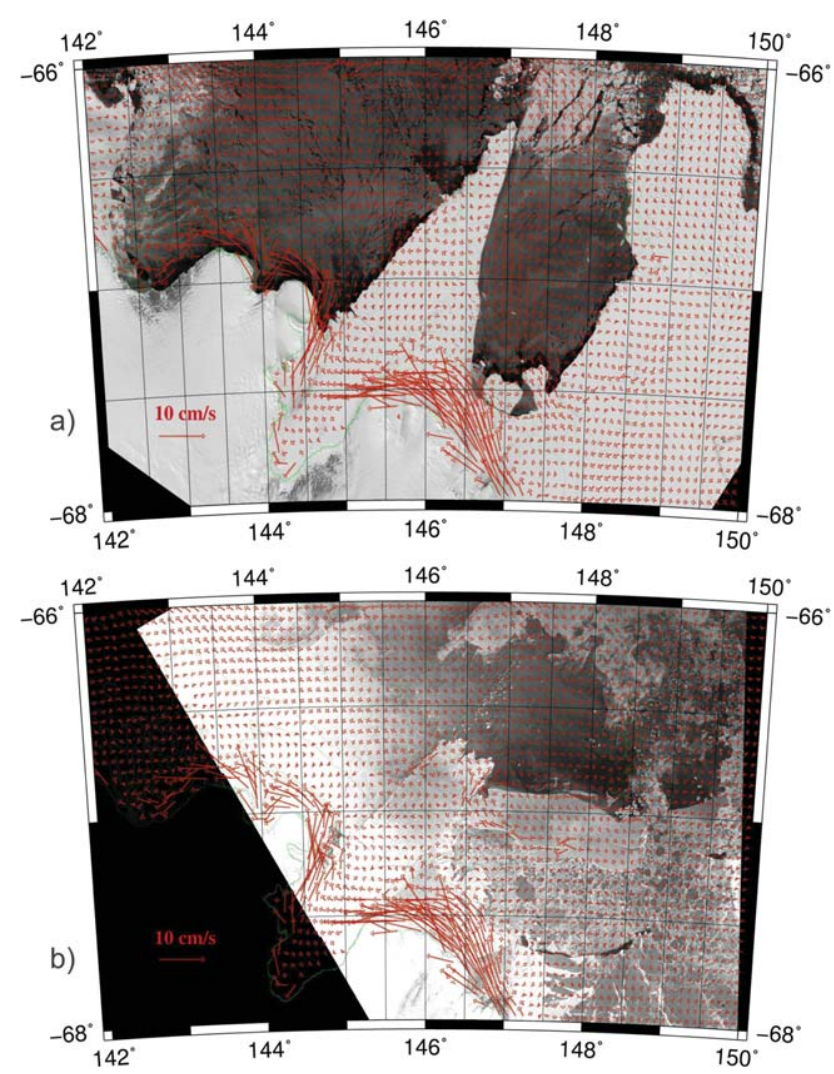

Figure 3. Mean barotropic currents velocity in B9B1 and B9B2 configurations.

$$
\begin{gathered}
F_{t a}=\frac{1}{2} \cdot \rho_{a i r} \cdot V_{a i r}^{2} \cdot C_{d a} \cdot L \cdot w=4 \cdot 5 \times 10^{8} \mathrm{~N} \\
F_{p a}=\frac{1}{2} \cdot \rho_{a i r} \cdot V_{a i r}^{2} \cdot L \cdot h_{a}=2 \cdot 1 \times 10^{8} \mathrm{~N} \\
F_{t w}=\frac{1}{2} \cdot \rho_{w} \cdot V_{w}^{2} \cdot C_{d w} \cdot L \cdot w=9.1 \times 10^{7} \mathrm{~N} \\
F_{p w}=\frac{1}{2} \cdot \rho_{w} \cdot V_{w}^{2} \cdot L \cdot h_{w}=1.6 \times 10^{8} \mathrm{~N} \\
F_{s s}=M \cdot g \cdot \sin (\alpha)=1.2 \times 10^{9} \mathrm{~N}
\end{gathered}
$$

[34] $F_{s S}$ is the largest of these forces in our case and this directly comes from the particularly large size and mass of the B9B and C28 icebergs. The sea surface slope results from the circulation which is dominated by tides in the area. The sea surface slope direction with regard to the current direction varies largely in this coastal area.

[35] $\mathrm{Fe}$ translates a number of different processes (e.g., tidal height, melt freeze, ground interactions). These processes intervene at various time scales and intensities, impacting the timing and trajectories of the icebergs in such areas.

\subsection{Mean Barotropic Circulation}

[36] Results for the two configurations B9B1 and B9B2 of the mean barotropic currents averaged over the 3 months run, with atmospheric and tidal forcing are shown in Figure 3.The mean currents provided by the model show generally small amplitudes of a few $\mathrm{cm} / \mathrm{s}$ with stronger values along the coast where it reaches a few tens of centimeter per second.

[37] When the B9B1 situation was prevailing (Figure $3 \mathrm{a})$, the background currents and sea surface slope around B9B were directed southward. And effectively, B9B slowly drifted south in the few years before 2010. Once it started to move southward a bit faster in December 2010, it faced a strong alongshore current associated with a northward sea surface slope and rotated clockwise to reach the B9B2 position, following the circulation and surface slope pattern. When we change the configuration of the model to B9B2, we obtain a change in the background barotropic circulation which induces a change to the currents east of the MGT from northward to westward. When the two rifts that were prevailing on the ice tongue finally broke through the whole width of the ice tongue and released the C28 iceberg around 12 February 2010, this iceberg moved away on the west side of the ice tongue. The last image we have before the calving is from 10 February 2010 and the first image where we can see clearly the rift having cut through and the iceberg starting moving sideways is from 13 February 2010.

[38] An additional pair of elements which are important to consider is that shallow depths in the bathymetry are present on the Mertz and Ninnis Banks (see Figure 1). Even though the forces acting on the icebergs are rotating during tidal cycles, the icebergs' movements are constrained by these banks and the forces will tend to be more effective when driving the icebergs away from the banks. These shallow depths are located close to the northwestern tip of the MGT (Mertz Bank), and where the B9B northern part was grounded on the B9B1 configuration. Both $\mathrm{C} 28$ and $\mathrm{B} 9 \mathrm{~B}$ cannot cross these areas without grounding or facing a barrier. Just after the calving, C28 started moving to the west, but its north west tip touched the Mertz Bank and the iceberg rotated around this grounding or contact point. This led to a break and the formation of a smaller iceberg at the beginning of March 2010 from this corner of C28, as shown on Figure 4.

[39] The background currents change with the changing position of the giant icebergs since the map of water column thickness changes significantly as the icebergs move. The trajectories of the calved or ungrounded icebergs follow closely the modeled barotropic circulation (mainly sea surface slope). The strong westward currents in front of the new ice front, just after the calving, are illustrated by the bottom sequence of images in Figure 4. Using these images, we tracked the trajectory of small icebergs and floes of former fast ice, and estimated their speed which reaches 6 to $8 \mathrm{~cm} / \mathrm{s}$ over a few days, which is in line with our model velocities. Due to scale effect, these small ice bodies are much less subject to the surface slope body force, and more influenced by the surface forces and directly follow the current in the absence of wind.

\subsection{Instantaneous Barotropic Currents}

[40] We now describe the effect of changing the position of giant icebergs on the instantaneous barotropic currents. To this end we represented four snapshots of tidal situations for high, descending, low, and ascending tides for both the B9B1 (Figure 5) and B9B2 (Figure 6) configurations. These simulations correspond to the 10-11 February, i.e., just before the calving event happened.

[41] The amplitude of the barotropic currents at one particular time is much larger than the mean current, reaching $30 \mathrm{~cm} / \mathrm{s}$ over the shallow banks and under the MGT and icebergs. The strength of the currents drops to a few 


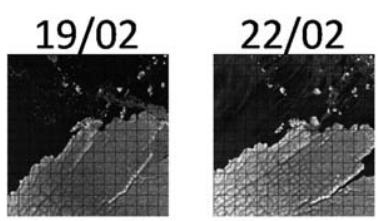

$26 / 02$

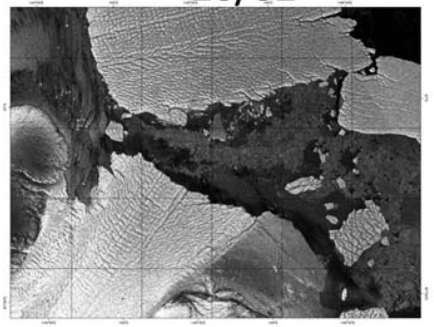

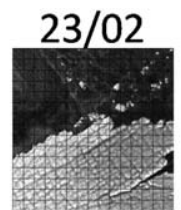

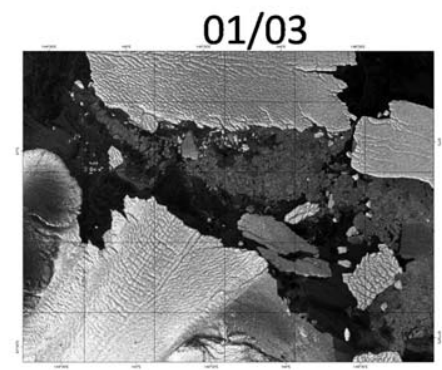

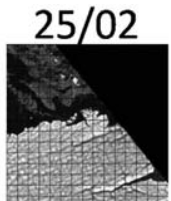

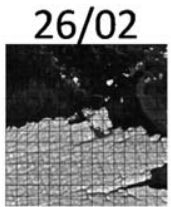

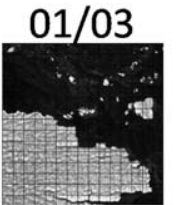

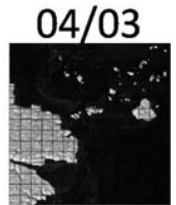

\section{$04 / 03$}

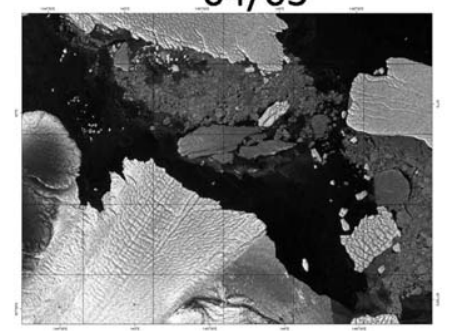

Figure 4. Series of ASAR images zoomed on the northwestern tip of C28 and on the CRAC area (the zoom areas correspond to the red boxes of Figure 1). One can see the grounding happening on the northern end of the MGT, releasing a 4 by $4 \mathrm{~km}$ iceberg bit (first sequence, on top, with $1 \mathrm{~km}$ grid spacing) and the fast moving ice bodies in front of the new MGT front following strong westward currents (second sequence, bottom line, with a $20 \mathrm{~km}$ grid spacing).

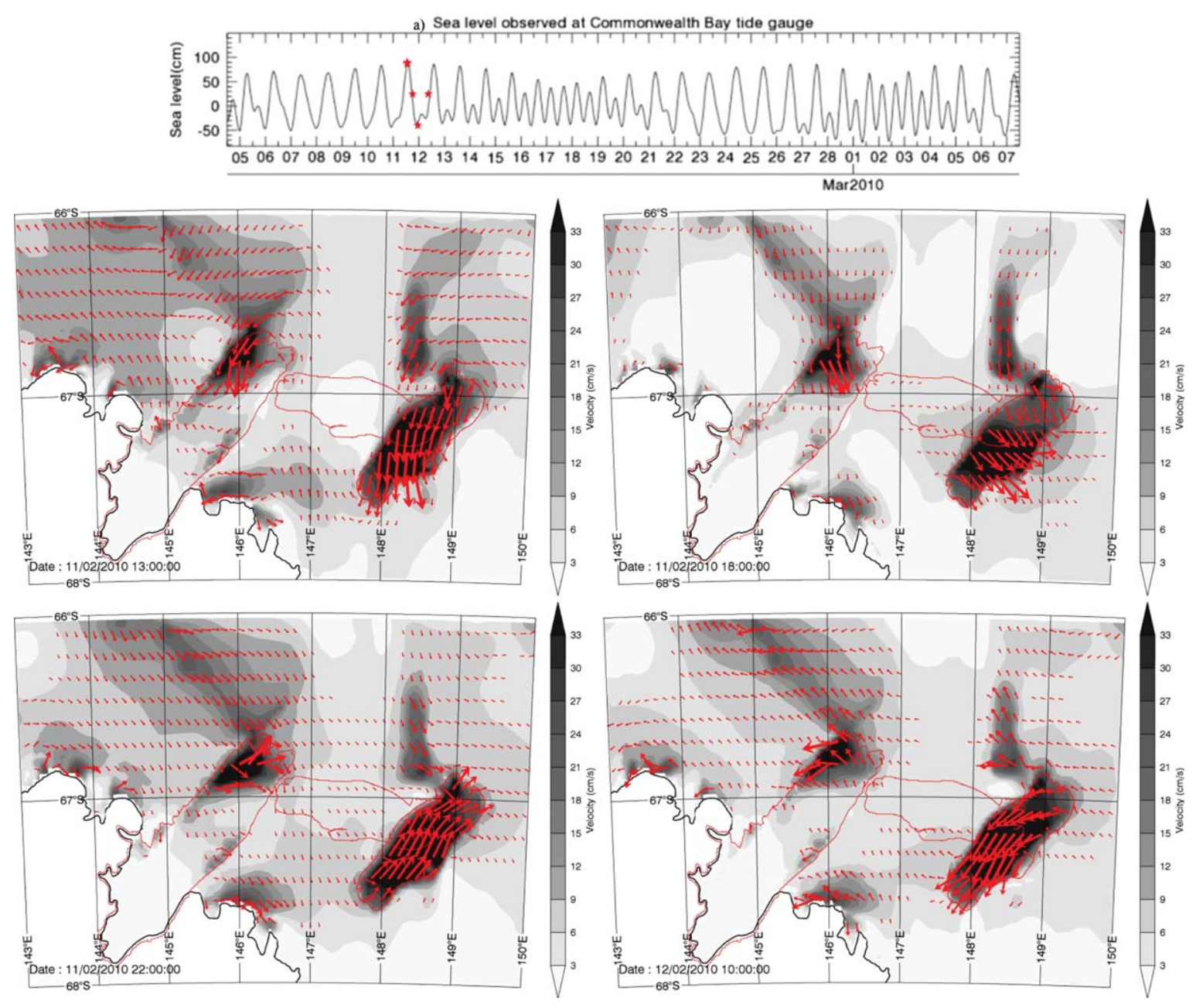

Figure 5. (a) Tidal elevation time series as observed by the Commonwealth Bay tide gauge, with red stars indicating the four snapshots. Instantaneous barotropic velocity field in B9B1 configuration in high, descending low, and ascending tide for the 10-11 February 2010. The map background shows the current magnitude in gray scale. Arrows show the direction of the instantaneous current. 

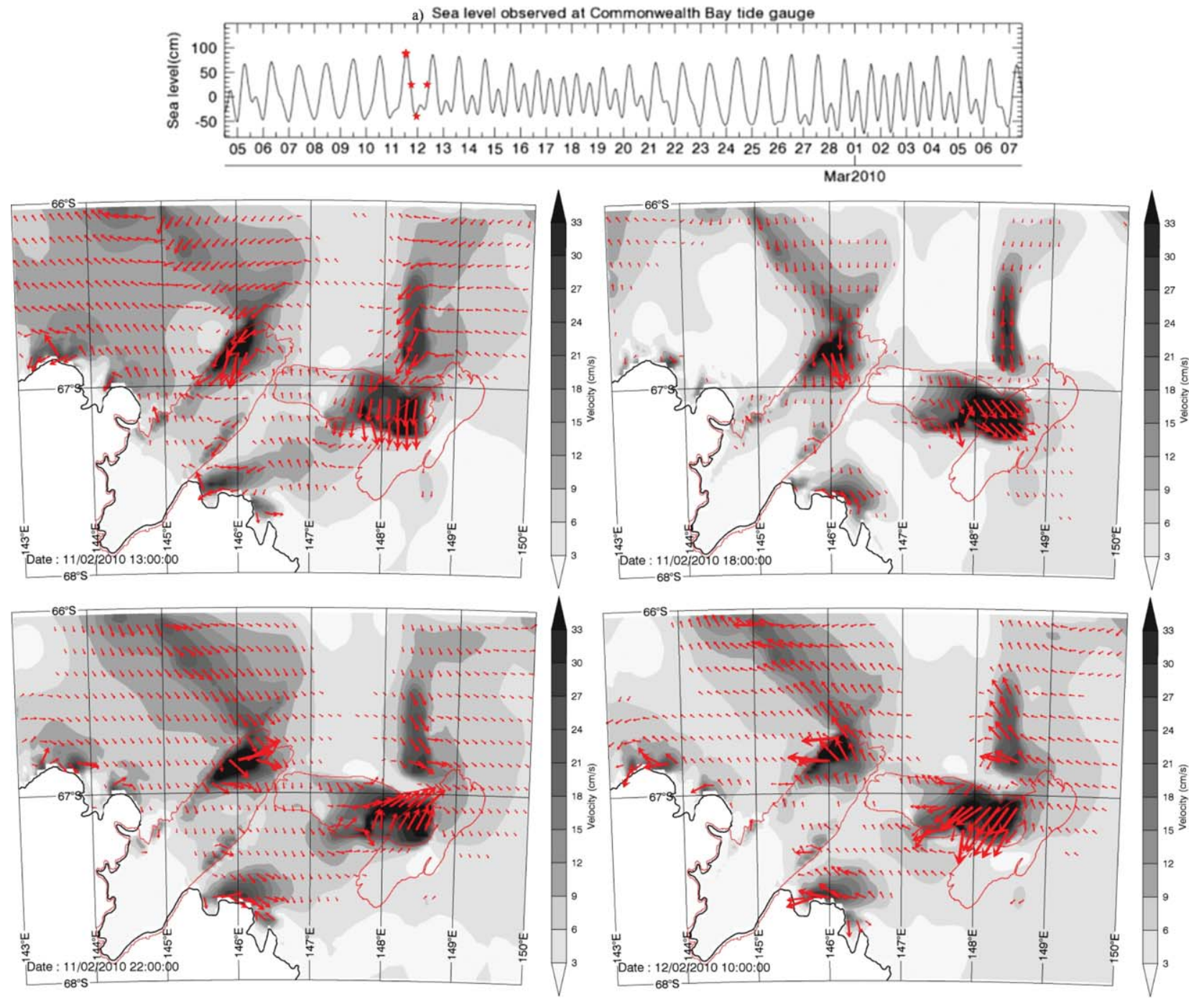

Figure 6. (a) Tidal elevation time series as observed by the Commonwealth Bay tide gauge, with red stars indicating the four snapshots. Instantaneous barotropic velocity field in B9B2 configuration in high, descending low, and ascending tide for the 10-11 February 2010. The map background shows the current magnitude in gray scale. Arrows show the direction of the instantaneous current.

centimeter per second offshore, in water depths of several hundreds of meters. The currents turn as the tidal cycle runs. For example, in the B9B1 configuration (Figure 5) the barotropic tidal currents around (and under) the B9B iceberg are directed to the south during the high tide, more to the south east during the ebb tide, then north east during the low tide, and south west during the flood tide. All of these phases involve currents above $20 \mathrm{~cm} / \mathrm{s}$ at any stage of the tidal cycle. This means that significant forces, mainly from sea surface slope, drag and friction under the iceberg, are acting every day, in all directions, on the B9B iceberg. Therefore, the tidal cycles could help release an iceberg from its grounding position, or to ground it depending on the bathymetric configuration and the iceberg draft as the tidal forces (currents and sea surface slope) can be large compared to forces from mean circulation. Also, when the water column under the iceberg becomes shallow, small horizontal displacements of the iceberg can lead to large changes in water column thickness and hence in current intensity.

[42] The effect of changing the barotropic circulation under the MGT on thermodynamic interactions between the ocean and ice shelf is also interesting (as suggested by Robertson [2005]), but cannot be explored with our present model.

\subsection{Calving of MGT (C28)}

[43] The B9B reached the B9B2 position about a week before the MGT finally calved, suggesting that the first impact was not strong enough to cause C28 to calve. Additionally, the calving occurred across the rifts that had developed during the 15 previous years principally under the daily cycle of tides [Lescarmontier, 2012]. The change in the background current between B9B1 and B9B2 situations (Figure 3) shows a significant increase in the current directed from east to west toward the ice tongue, mainly around the westernmost tip of B9B2. 

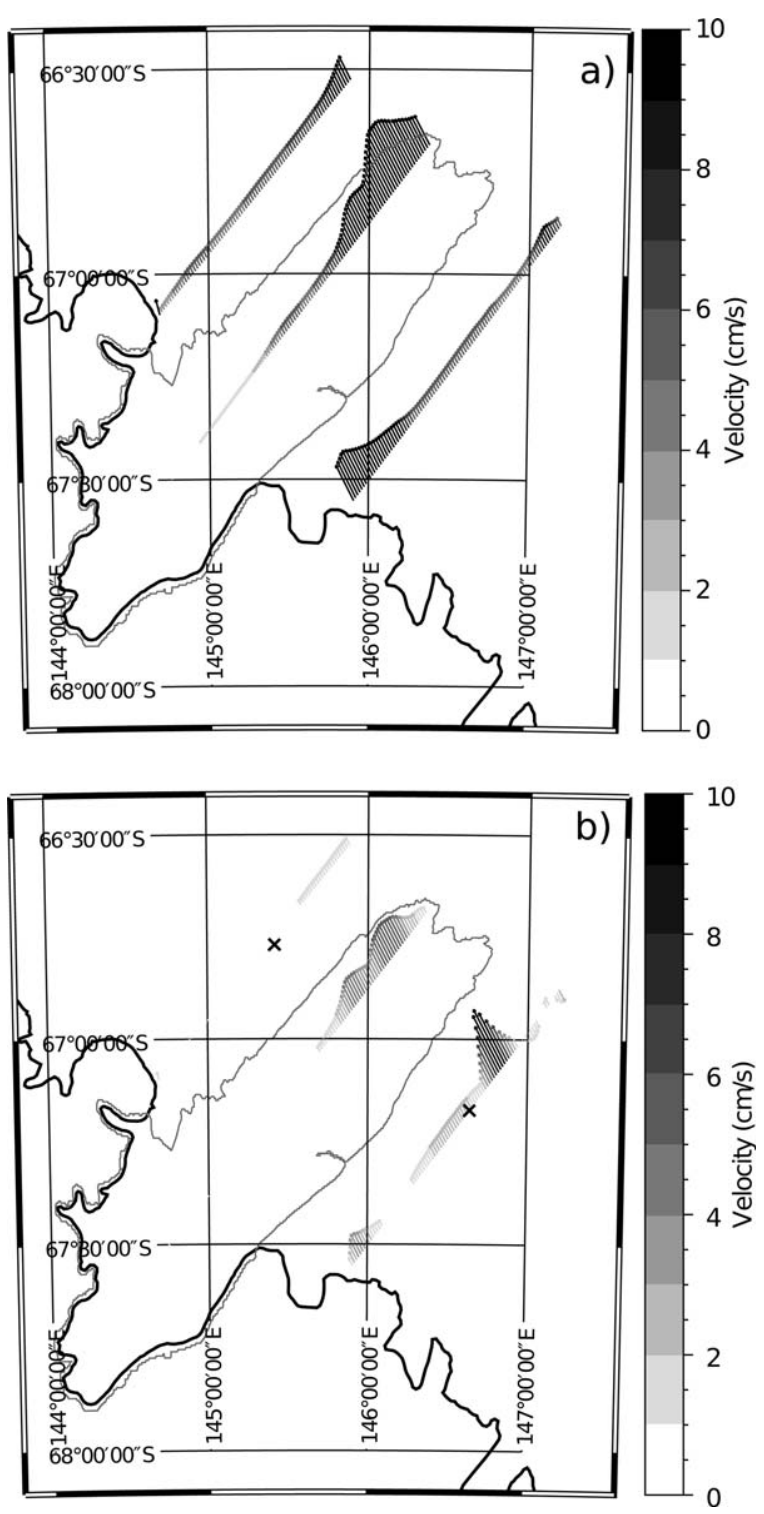

Figure 7. Map of the instantaneous projected velocities across the sections (the 12 February 2010 at 10:00) in (a) B9B1 configuration and (b) difference B9B2 minus B9B1. The black crosses show the location of the points used to compute the across glacier sea surface slope shown in Figure 8 .

[44] We defined three parallel sections (Figures 7a and 7b) along the MGT on its east, west sides, and along its center line. The modeled barotropic velocity and sea surface height were interpolated along the sections and projected onto normal and tangential components. Figures $7 \mathrm{a}$ and $7 \mathrm{~b}$ show that the difference between B9B1 and B9B2 configurations in terms of currents mainly concentrates around the B9B2 position (e.g., the western section shows almost no change). Figure 8 show the time series and histograms of across glacier velocity (left) and across glacier sea surface slope (right). Because we have run the model separately for the tide and atmospheric forcing we can separate both components in the time series (Figure 8, top).
[45] The time series of the average velocities over the eastern section for the calving event period (from 10 to 20 February, Figures $8 \mathrm{a}$ and $8 \mathrm{c}$ ) show typically $10 \mathrm{~cm} / \mathrm{s}$ daily amplitude during spring tides. The velocity resulting from the atmospheric forcing is only significant during strong wind or katabatic burst events and can reach $4 \mathrm{~cm} / \mathrm{s}$, becoming comparable to the tidal effects. This atmospheric component is almost always oriented to the west, following the katabatic wind direction. The time series of the across glacier sea surface slope during the same period show typical amplitudes of $0.6 \mathrm{~mm} / \mathrm{km}$ with a strong atmospheric component that can reach the same amplitude as the tidal effect. The impact of the change in configuration between B9B1 and B9B2 is illustrated in Figures 8c and 8d. The currents in the B9B2 configuration are generally stronger and generally stronger when toward the glacier. The variance in currents is increased by $75 \%$ from B9B1 to B9B2 situations (Figure 8e). The sea surface slope does not change significantly between B9B1 and B9B2 configurations (Figure 8d). The mean slope decreases by $50 \%$ between $\mathrm{B} 9 \mathrm{~B} 1$ and $\mathrm{B} 9 \mathrm{~B} 2$, but remains small in regard to the large variability (Figure $8 \mathrm{f}$ ).

[46] In terms of forces, the change of oceanic forces $\left(F_{p w}\right.$ and $\left.F_{t w}\right)$ between B9B1 and B9B2 associated with the change in currents intensity is large, but small in regards to the change of $F_{s s}$. Therefore, the change in total oceanic forces $\left(F_{p w}+F_{t w}+F_{s s}\right)$ remains very small compared to the time variability of the $F_{s s}$ itself. We estimated the atmospheric forces using the ECMWF data (which are used to force the barotropic model). Time series of the across glacier forces for the whole month of February 2010 are shown in Figure 9 and the computed variability of all the forces with the B9B2 configuration are shown in Table 4. One can see that the forces from oceanic currents are small, the atmospheric forces are episodically significant, and $F_{s s}$ dominates overall.

[47] A detailed survey of satellite images during the calving period shows that the B9B iceberg reached its B9B2 position on the 6 February 2010 which corresponds to a peak in velocity and sea surface slope, associated with a strong wind (Figures $8 \mathrm{a}$ and $8 \mathrm{~b}$ ). The actual calving occurred between the 10 and 13 February when the maximum current and slope are reached, associated with both spring tide and strong wind (Figures $8 \mathrm{a}$ and $8 \mathrm{~b}$ ). However, these peak values are not unusually above normal.

[48] The influence of water column change mainly impacts the currents in an area within a few tens of kilometers around the iceberg. The $30 \%$ local increase in current standard deviation implies an increase of heat exchanges. This can have implications on the local circulation, mixing, ice melt, etc.

Table 4. Standard Deviation of the Different Forces Acting on MGT

\begin{tabular}{lc}
\hline Origin of Force & Standard Deviation $(\mathrm{N})$ \\
\hline Surface atmospheric drag $\left(F_{t a}\right)$ & $3.4 \times 10^{8}$ \\
Lateral atmospheric pressure $\left(F_{p a}\right)$ & $1.6 \times 10^{8}$ \\
Surface water drag $\left(F_{t w}\right)$ & $2.5 \times 10^{7}$ \\
Lateral water pressure $\left(F_{p w}\right)$ & $4.5 \times 10^{7}$ \\
Sea surface slope $\left(F_{s s}\right)$ & $2.7 \times 10^{9}$ \\
\hline
\end{tabular}




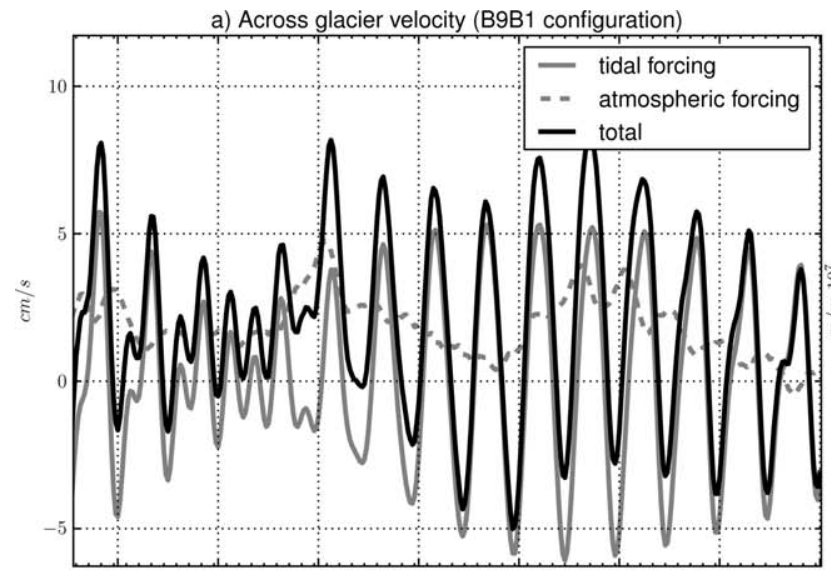

b) Across glacier velocity (tidal and atmospheric forcing)
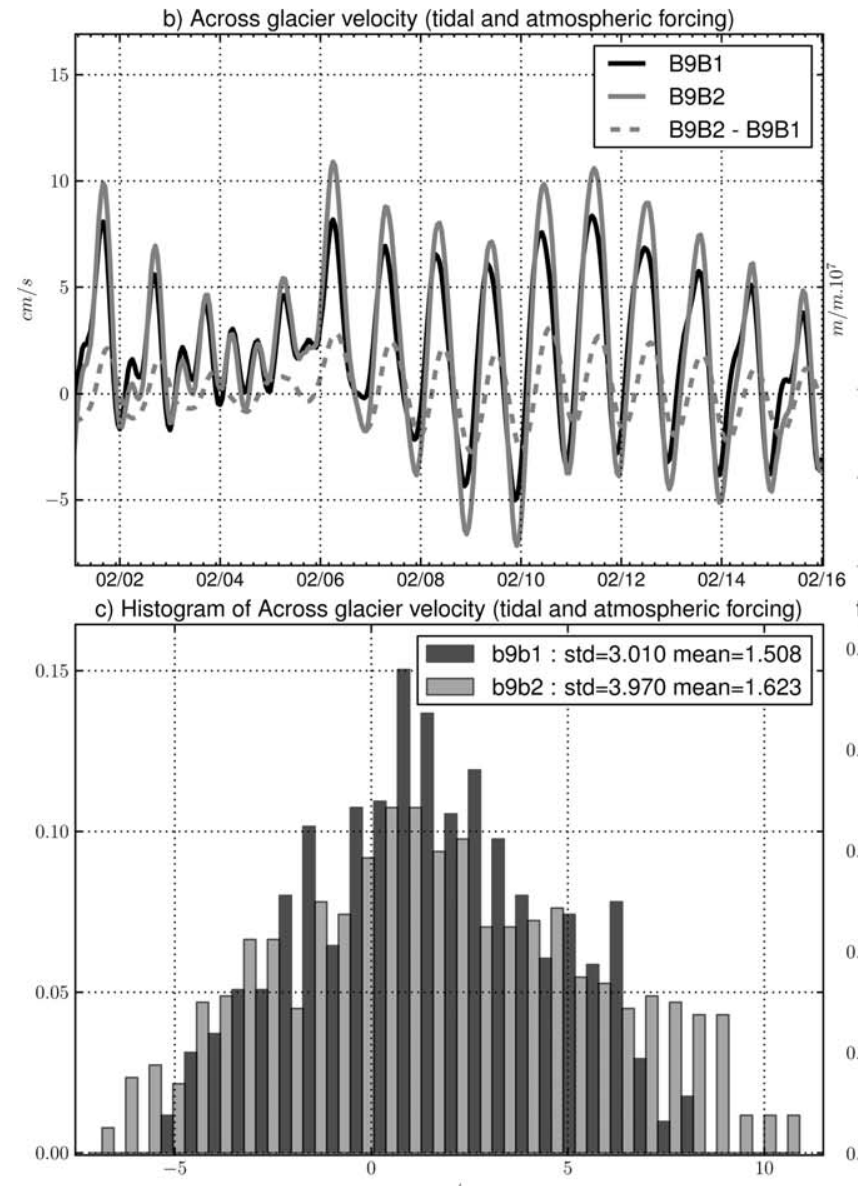

$\mathrm{cm} / \mathrm{s}$

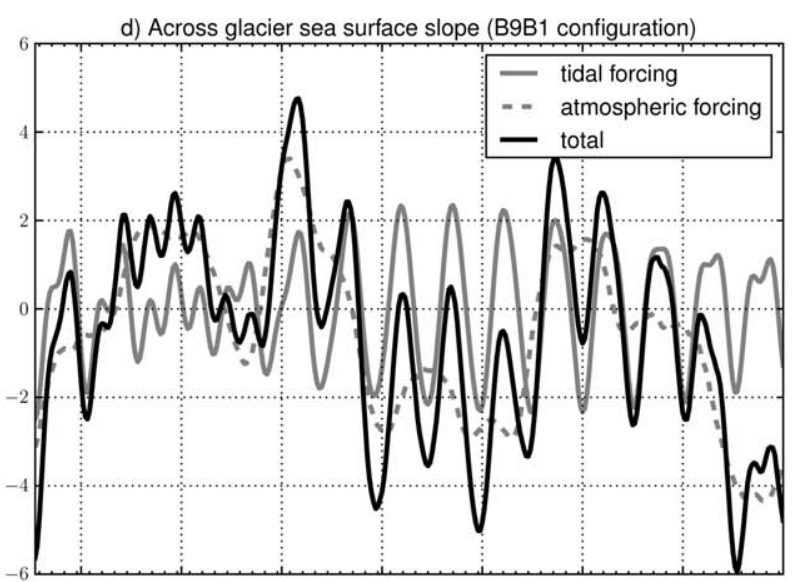

e) Across glacier sea surface slope (tidal and atmospheric forcing)
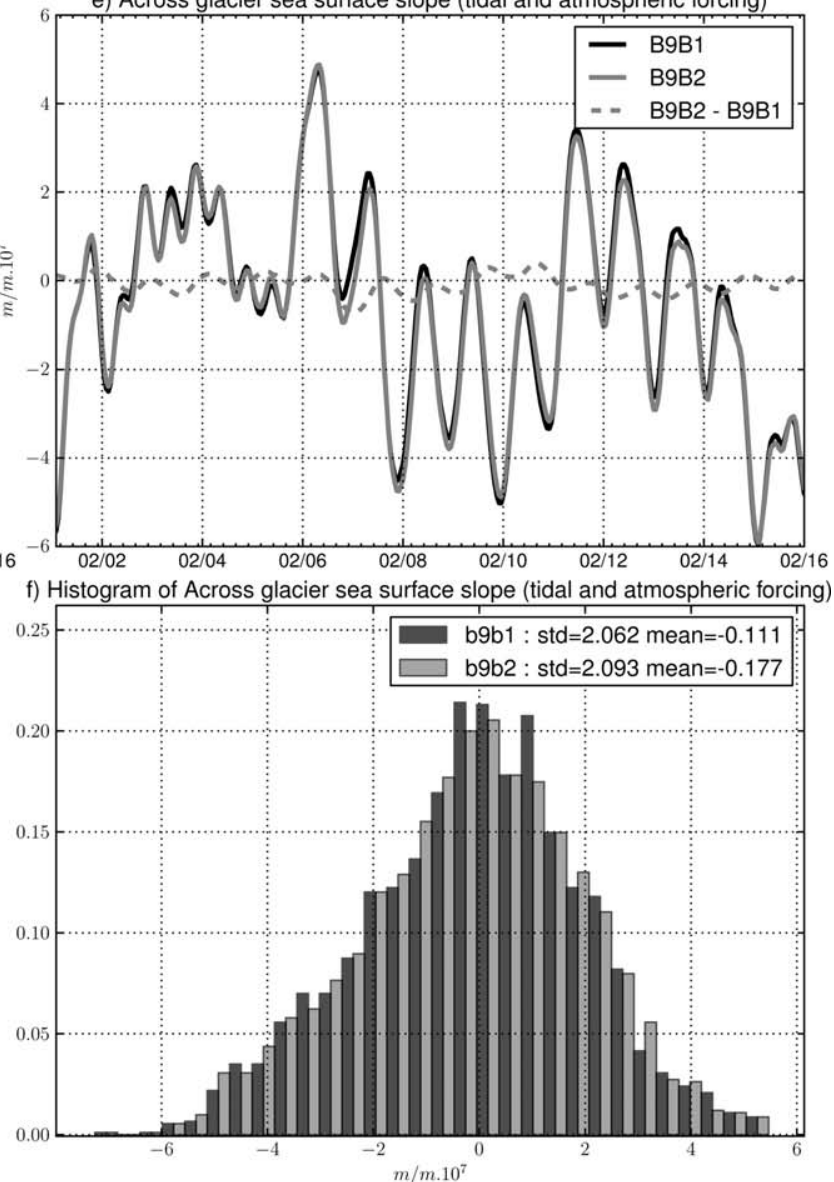

Figure 8. Time series and histograms of the (left) across glacier ocean currents velocity in $\mathrm{cm} / \mathrm{s}$ and (right) sea surface slope in $\mathrm{m} / \mathrm{m}$. (a and b) The contribution of the different forcing (tidal, atmospheric, and both), (c and d) the time series with both tidal and atmospheric forcing for B9B1, B9B2 configurations and the difference, and (e and $\mathrm{f}$ ) normalized histograms of the 3 month model outputs with both forcing for B9B1 and B9B2 configurations. The slope is computed between the two points shown in Figure $7 b$.

[49] GPS observations of the rift opening during the B9B1 configuration show a clear tidal influence on the rifting [Legresy et al., 2004; Lescarmontier, 2012]. The oceanic circulation (tides, response to the atmosphere, sea surface slope) presented here also clearly influence the movement of icebergs and participated in weakening the link between $\mathrm{C} 28$ and the MGT. However, we cannot determine the precise factors that controlled the actual calving of $\mathrm{C} 28$.

\section{Conclusion}

[50] In this paper, we developed a 2-D high-resolution barotropic model of the Dumont d'Urville-Mertz Glacier 


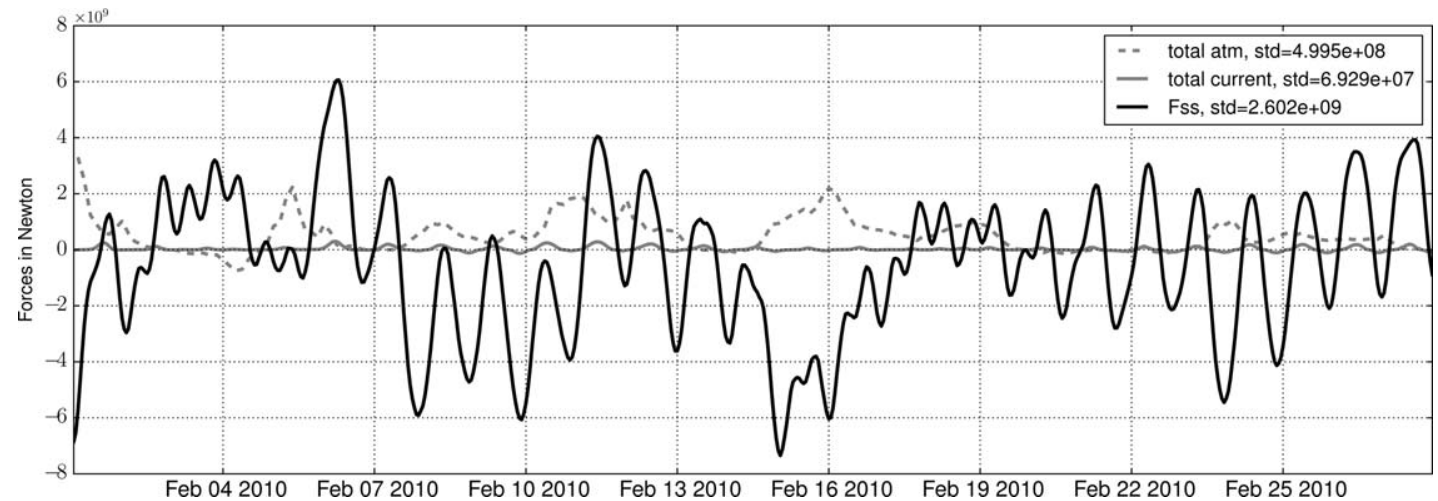

Figure 9. Forces (in $\mathrm{N}$ ) acting on $\mathrm{C} 28$, in the across glacier direction, from the atmosphere $\left(F_{p a}+F_{t a}\right)$ in dashed gray, ocean currents $\left(F_{p w}+F_{t w}\right)$ in gray, and sea surface slope $\left(F_{s s}\right)$ in black.

area, using updated bathymetry and coastline. We validated the model results against tide gauges, floating GPS, and mooring bottom pressure gauges. The RSS difference between the model and available observations is $2.3 \mathrm{~cm}$, showing our model is currently the most accurate available for this region. The impact of improved bathymetry and coastline has proved to be very significant, highlighting the need for such mapping efforts in Antarctica. The capability of the model to take into account the draft of floating ice bodies by modifying the effective bathymetry allowed us to investigate the role of the circulation on the evolution of the MGT and the surrounding icebergs. Comparisons of simulations based on the different position of iceberg B9B before and at the time of the Mertz Glacier calving demonstrate that the mean barotropic velocity field was enhanced by the presence of the B9B near the tip of the MGT. The instantaneous currents, due mainly to tides, are an order of magnitude larger than the mean currents. This strong current increase reaching $75 \%$ in variance near the MGT, while not very strong in term of mechanical forces, must impact the environment of the ice tongue (heat exchange, sea ice, etc.). Doing a force balance analysis across the MGT, we found that the Fss (resulting from the sea surface slope) dominates. The calving event occurred between the 10 and 13 February 2010, during spring tide, when all forces were large. It was one of the two maxima of the month, the first one occurring the 6th when B9B first entered in contact with the MGT. However, the combination of all forces at these times was not unusually large, making it difficult to precisely determine the actual cause of the final calving stage. Further quantitative estimates of the impact of the change from B9B1 to B9B2 configuration would require a dedicated study with a model able to include the mechanical and thermodynamical fluid interactions with ocean and atmosphere (including snow melt which we observed on the SAR imagery in the times just prior to the calving). The displacement of large floating ice masses is able to modify the ocean circulation in coastal regions where the iceberg draft can significantly modify the thickness of the water column. This coupling between iceberg position and local circulation could be strong in Antarctica coastal regions, making it difficult to accurately predict iceberg trajectories as they get partially grounded. A realistic and accurate iceberg drift model would require accurate information on the bathymetry, the ice draft, a bottom drag model and should also take into account the direct effect of wind on the upper surface of the ice bodies.

[51] Acknowledgments. This study is part of the CRACICE project, supported by the CNES, ANR DACOTA grant, IPEV, CNRS/INSU, University Paul Sabatier Toulouse, and the ACE-CRC, University of Tasmania. We thank Rosemary Morrow from LEGOS for helpful reading and comments on the manuscript. We thank Ben Galton-Fenzi and Rob Massom from ACE-CRC, Hobart. They provided appreciated helpful discussions on the work and English language corrections. We thank MarieNoelle Houssais from LOCEAN, Paris and leading the ALBION oceanographic program for providing the ADCP mooring pressure data. The SPOT images used in this study were obtained within the ISIS-CNES CRACICE project. The ENVISAT-ASAR images were obtained from the ESA AOPOL4096 project. The MODIS images were obtained through the NASA-EOSDIS website.

\section{References}

Andersen, O. B., P. L. Woodworth, and R. A. Flather (1995), Intercomparison of recent ocean tide models, J. Geophys. Res., 100(C12), 282-282.

Beaman, R. J., P. E. O’Brien, A. L. Post, and L. De Santis (2010), A new high-resolution bathymetry model for the Terre Adelie and George V continental margin, East Antarctica, Antarct. Sci., 23(1), 95-103.

Carrere, L., and F. Lyard (2003), Modeling the barotropic response of the global ocean to atmospheric wind and pressure forcing-Comparisons with observations, Geophys. Res. Lett., 30(6), 1275, doi:10.1029/ 2002GL016473.

Domack, E. W. (1982), Sedimentology of glacial and glacial marine deposits on the George V Adelie continental shelf, East Antarctica, Boreas, 11(1), 79-97.

Egbert, G. D., and S. Y. Erofeeva (2002), Efficient inverse modeling of barotropic ocean tides, J. Atmos. Oceanic Technol., 19(2), 183-204.

Keghouche, I., L. Bertino, and K. A. Lisaeter (2009), Parameterization of an Iceberg Drift Model in the Barents Sea, J. Atmos. Oceanic Technol., 26(10), 2216-2227.

Keys, H., S. Jacobs, and D. Barnett (1990), The calving and drift of iceberg B-9 in the Ross Sea, Antarctica, Antarct. Sci., 2(3), 243-257.

Lacarra, M., M.-N. Houssais, E. Sultan, S. Rintoul, and C. Herbaut (2011), Summer hydrography on the shelf off Terre Adelie/George V Land based on the ALBION and CEAMARC observations during the IPY, Polar Sci., 5, 88-103, doi:10.1016/j.polar.2011.04.008.

Le Bars, Y., F. Lyard, C. Jeandel, and L. Dardengo (2010), The AMANDES tidal model for the Amazon estuary and shelf, Ocean Modell., 31(3-4), 132-149.

Le Provost, C., F. Lyard, J. Molines, M. Genco, and F. Rabilloud (1998), A hydrodynamic ocean tide model improved by assimilating a satellite altimeter-derived data set, J. Geophys. Res., 103(C3), 5513-5529.

Legresy, B., A. Wendt, I. Tabacco, F. Remy, and R. Dietrich (2004), Influence of tides and tidal current on Mertz Glacier, Antarctica, J. Glaciol., 50(170), 427-435.

Lescarmontier, L. (2012), Rifting and calving processes of Antarctica icebergs: Story of the Mertz Glacier, PhD thesis, Univ. Paul SabatierToulouse III, France, and Univ. of Tasmania, Australia. 
Lescarmontier, L., B. Legresy, R. Coleman, F. Perosanz, C. Mayet, and L. Testut (2012), Vibrations of Mertz Glacier ice tongue, East Antarctica, J. Glaciol., 58(210), 665-676.

Lorenzin, G. (2003), Australian Antarctic territory coastline 2003, technical report, Aust. Antarct. Data Cent.-Cat. of Aust. Antarct. and Subantarct. Metadata. [Available at http://data.aad.gov.au/aadc/metadata/.]

Lyard, F., F. Lefevre, T. Letellier, and O. Francis (2006), Modelling the global ocean tides: Modern insights from FES2004, Ocean Dyn., $56(5-$ 6), 394-415.

Lynch, D. R., and W. G. Gray (1979), A wave equation model for finite element tidal computations, Comput. Fluids, 7(3), 207-228.

Massom, R. A., A. B. Giles, H. A. Fricker, R. C. Warner, B. Legresy, G Hyland, N. Young, and A. D. Fraser (2010), Examining the interaction between multi-year landfast sea ice and the Mertz Glacier Tongue, East Antarctica: Another factor in ice sheet stability?, J. Geophys. Res., 115, C12027, doi:10.1029/2009JC006083.
Padman, L., H. A. Fricker, R. Coleman, S. Howard, and L. Erofeeva (2002), A new tide model for the Antarctic ice shelves and seas, Ann. Glaciol., 34(1), 247-254.

Pairaud, I., F. Lyard, F. Auclair, T. Letellier, and P. Marsaleix (2008), Dynamics of the semi-diurnal and quarter-diurnal internal tides in the Bay of Biscay. Part 1: Barotropic tides, Cont. Shelf Res., 28(10-11), 1294-1315.

Potzsch, A., B. Legresy, W. Korth, and R. Dietrich (2000), Glaciological investigations of Mertz glacier, East Antarctica, using SAR interferometry and field observations, paper presented at ERS-ENVISAT Symposium: Looking down to Earth in the New Millenium.

Ray, R. D. (1999), A global ocean tide model from Topex/Poseidon altimetry, Tech. Rep. 209478, 58 pp., Goddard Space Flight Cent., Greenbelt, Md

Robertson, R. (2005), Baroclinic and barotropic tides in the Ross Sea, Antarct. Sci., 17(01), 107-120. 